\title{
Drosophila melanogaster: a fly through its history and current use
}

\author{
${ }^{1} \mathrm{R}$ Stephenson, ${ }^{2} \mathrm{NH}$ Metcalfe \\ ${ }^{1}$ Fifth year medical student at Hull York Medical School; ${ }^{2}$ General Practioner, York and Lead of History of Modern Medicine SSC, Hull York \\ Medical School, University of York, UK
}

\begin{abstract}
Drosophila melanogaster, the common fruit fly, has been used as a model organism in both medical and scientific research for over a century. Work by Thomas Hunt Morgan (1866-1945) and his students at Columbia University at the beginning of the twentieth century led to great discoveries such as sex-linked inheritance and that ionising radiation causes mutations in genes. However, the use of Drosophila was not limited to genetic research. Experimentation with this model organism has also led to discoveries in neuroscience and neurodevelopment, including the basis of circadian rhythms. Its complex nervous system, conserved neurological function, and human disease-related loci allow Drosophila to be an ideal model organism for the study of neurodegenerative disease, for which it is used today, aiding research into diseases such as Alzheimer's and Parkinson's, which are becoming more prevalent in today's ageing population.
\end{abstract}

KEYWORDS Drosophila melanogaster, Thomas Hunt Morgan, Alfred Henry Sturtevant, Hermann Joseph Muller, Notch pathway, neurodegenerative disease

\author{
Correspondence to $R$ Stephenson, \\ 43 Breamish Drive, \\ Rickleton, Washington, \\ Tyne and Wear NE38 9HS, UK
}

tel. $+44(0) 7891723688$

e-mail hy7ras@hyms.ac.uk

DECLARATIONS OF INTERESTS No conflicts of interest declared.

\section{THE USE OF DROSOPHILA MELANOGASTER IN MEDICAL AND SCIENTIFIC RESEARCH}

From their ancestral home in equatorial Africa' to laboratory benches throughout the world, Drosophila melanogaster (Figure I) are one of the most valuable model organisms in the world of neuroscience; but what is it that makes them an ideal model organism for research? Since being employed as a transgenic model for spinocerebellar ataxia 3 (SCA3) in 1998, Drosophila have been used in the study of a wide range of human neurodegenerative diseases including Huntington's, Alzheimer's and Parkinson's disease (PD). ${ }^{2}$ This is possible because the fly possesses a complex nervous

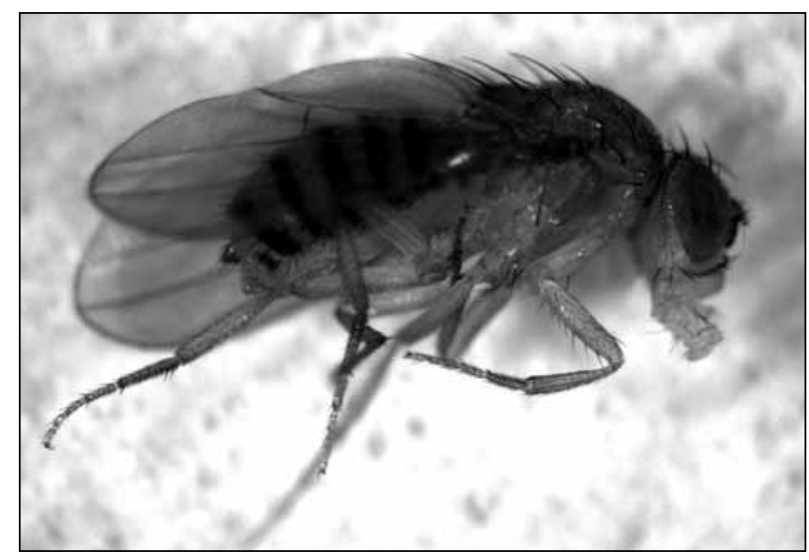

FIGURE I A Drosophila melanogaster fly (image courtesy of Chris Elliot). system that allows it to elicit complex neuronal tasks, such as learning and memory, similar to that in humans. ${ }^{3}$ This nervous system consists of around 100,000 neurones and, despite the brain of a fly having a different anatomical structure to that of a human, many key features of the development and function of this system remain the same. ${ }^{4}$ This includes conservation of fundamental cell biology such as membrane trafficking, regulation of gene expression and cell death, which are present in all vertebrate systems. ${ }^{5}$ In fact, $75 \%$ of human disease-related loci have a Drosophila orthologue. ${ }^{6}$ Another key feature making Drosophila an attractive model is the range of genetic tools (including the GAL4 [a transcriptional activator in yeast]/UAS [upstream activating system], mosaic analysis with a repressible cell marker [MARCM] system and ribonucleic acid interface [RNAi]) available to manipulate them and the ease of introducing human genes into the fly. Its other benefits include being much less costly and time consuming to use than a mouse model for example, ${ }^{3}$ due to their rapid reproduction time and short lifespan, giving a higher throughput in experiments. Being able to introduce human genes into Drosophila enables us to recapitulate the symptoms and progression of human disease in flies.

\section{FROM A COMMON PEST TO THOMAS HUNT MORGAN AND HIS STUDENTS}

Following the discovery of the white gene by Thomas Hunt Morgan (Figure 2) over 100 years ago, fruit flies have been making important contributions to many 
fields of medical and scientific research, ${ }^{7}$ including gene biology, cell biology, developmental biology and population genetics. Influenced by his work, Morgan's three students, Alfred Henry Sturtevant (1891-1970), Calvin Bridges (1889-1938) and Hermann Joseph Muller (1890-1967), went on to make advances in genetics. However, these were not the only scientists to appreciate the potential benefits of using Drosophila melanogaster as a model organism. During this time, there were also discoveries in neuroscience and neurodevelopment including: the importance of the Notch in embryonic development, identified by DF Poulson in 1915; the detection of many genes later found to be involved in conserved signalling pathways by Christiane NüssleinVolhard and Eric Wieschaus; and the basis of circadian rhythms described by Seymour Benzer in the late 1960s. ${ }^{7}$ Collectively, this work has formed a good basis for further neuroscientific research and Drosophila melanogaster is still one of the most valuable model organisms used today (Figure 3). Present day research using Drosophila melanogaster has considerably improved our understanding of the molecular concepts underlying neurodegenerative diseases including polyglutamine diseases,Alzheimer's disease and PD, which are becoming of increasing concern to the ageing populations of the Western world. ${ }^{2}$

In the early 1900s there was a movement to introduce new experimental model organisms into laboratories. The first person to use Drosophila melanogaster in this way was William Ernest Castle (1867-1962), a professor at Harvard University; he went on to disseminate the idea of using Drosophila in research to a network of experimental zoologists. Castle first used Drosophila in I90I, incorporating them into his work on the genetics of coat-colour in both mice and guinea pigs.' In this work he anticipated a negative result and therefore saw no point in using mammals which were slower breeding and more expensive; he therefore chose Drosophila, which were fast breeding and cheaper. In 1903, Castle's work influenced William J Moenkhaus (I87I-1947), a professor at Indiana University Medical School, who introduced the fruit fly into his laboratory, following experimental failures in higher model organisms including fish, mice and willow beetles. Later, the entomologist Frank E Lutz, at the Station for Experimental Evolution at the Carnegie Institution (Cold Spring Harbour) took Moenkhaus' advice and incorporated Drosophila into his work. He had already used wild crickets as model organisms through which he studied the variation in short and long-winged forms, but he set this research aside to study the development of Drosophila. He looked specifically at the development through the egg, larval and pupal stages and aimed to establish whether it was a result of individual characteristics, inherited traits or environmental factors. Unfortunately, due to the great variation in growth rates at all stages, he struggled to

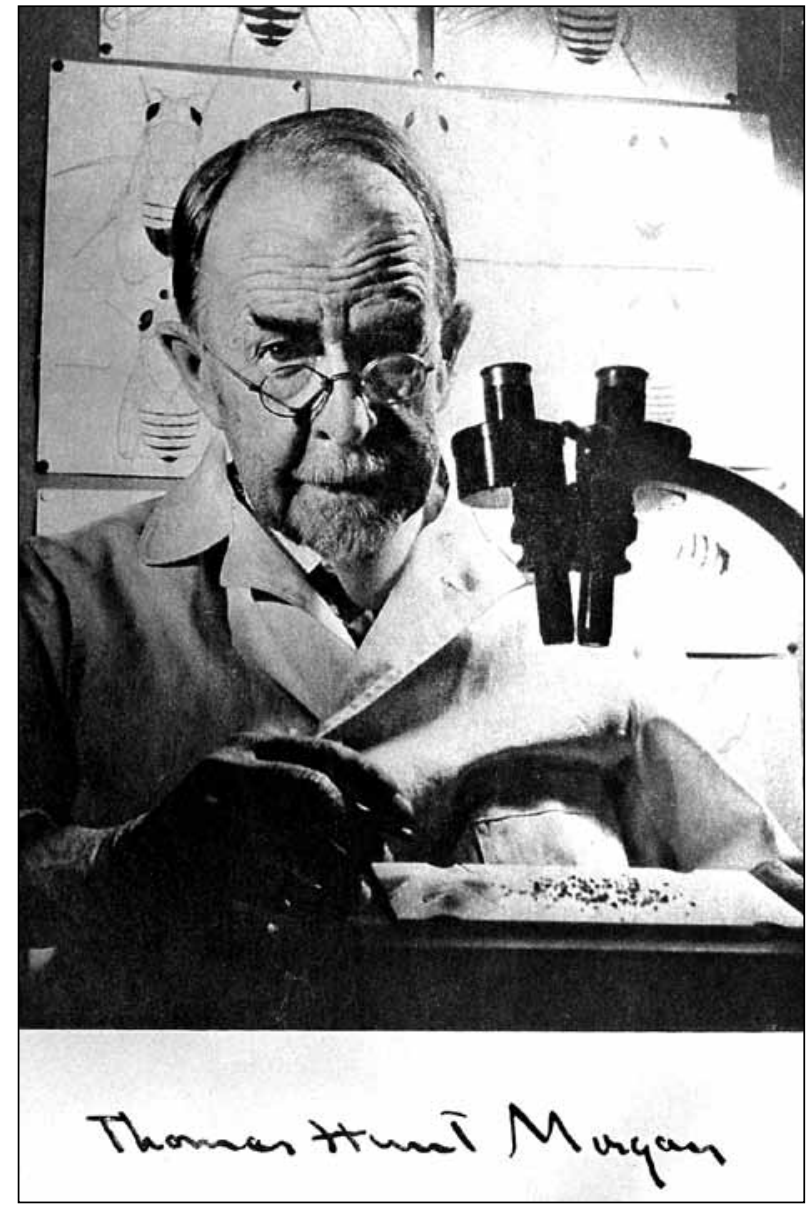

FIGURE 2 Thomas Hunt Morgan (1866-1945) working in his laboratory on Drosophila melanogaster with drawings of these flies behind him. (Image courtesy of the Wellcome Library, London.)

gain valid data or make valid conclusions and stopped using Drosophila.' It seems likely however that Lutz recommended their use to Morgan in 1906, whose work with this model organism produced great advances in genetic research.?

Morgan began his work with Drosophila melanogaster at Columbia University, New York. In what became known as 'the fly room', ${ }^{8}$ his original research eventually resulted in the complete DNA sequencing of all euchromatic regions of Drosophila chromosomes in $2000 .^{8}$

\section{SEX-LINKED INHERITANCE}

After breeding a culture of red-eyed Drosophila for almost a year, Morgan found a male fly with white eyes. He bred this white-eyed male fly with one of its redeyed sisters which resulted in I,237 flies with red eyes and three with white. It was further noted that all whiteeyed flies were male. As a result of this and additional experiments involving further inbreeding of these first generation offspring, he initially thought that this characteristic must be limited to the male sex only. 


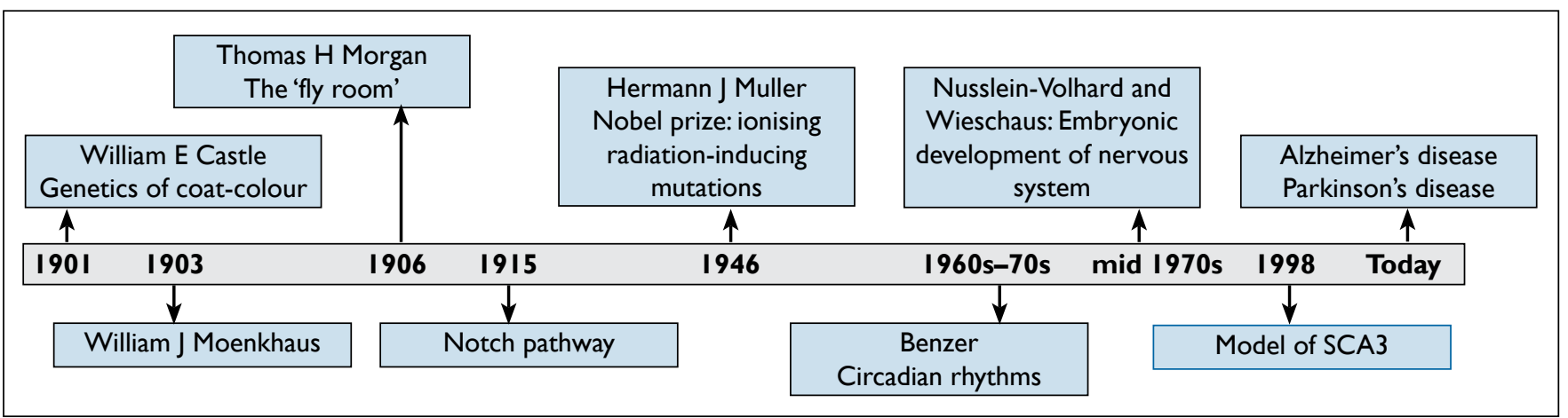

FIGURE 3 Timeline of the use of Drosophila melanogaster in the history of medical and scientific research

However, further inbreeding of a white-eyed male fly with some of its daughter flies resulted in white-eyed female offspring. This suggested that this trait was not limited to the male sex. ${ }^{10}$ His research led him to conclude that the white-eye characteristic, which he named the white gene, must be carried on the $X$ chromosome" which, in turn, led to the discovery of sex-linked inheritance. ${ }^{12}$

Following the work by Morgan, one of his students, Alfred Henry Sturtevant, recognised that the sex-linked factors Morgan described might be arranged linearly. ${ }^{12}$ By breeding groups of Drosophila with dissimilar phenotypes resulting from different mutations, Sturtevant found that sections of homologous chromosomes could interchange, or as he termed it, 'cross-over'. He assumed that the proportion of 'cross-overs' indicated the distance between them ${ }^{13}$ and consequently, from the five sex-linked mutations described by Morgan, he assembled a genetic map. ${ }^{2}$

\section{IONISING RADIATION AND MUTATIONS}

Hermann Joseph Muller was another of Morgan's students at Columbia University. It was later in his career, while working at the University of Texas, that he discovered that radiation could produce genetic mutations. ${ }^{14} \mathrm{He}$ won the Nobel Prize in 1946 in Physiology or Medicine for the conclusion that ionising radiation causes mutations such as chromosomal rearrangements. ${ }^{15}$ Muller reported in his article entitled Artificial Transmutation of the Gene published in 1927, that treating the sperm of Drosophila with X-rays produced mutations in genes that were stably inherited and could be followed through three or four further generations. Additionally, he found that there was a dose-response relationship between the dose of $X$-rays and number of mutations. Treated flies had a mutation rate of up to 150-fold greater than control flies bred in the same conditions. He also reported changes in the linear arrangements of genes as a result of X-ray treatment, including inversions, translocations and fragmentations. ${ }^{16}$

\section{IMPORTANT DISCOVERIES IN NEUROSCIENCE USING DROSOPHILA}

\section{Notch}

Research using Drosophila melanogaster uncovered some key aspects of neurodevelopment, including the discovery of Notch and its mutations. In higher vertebrates, it is now known that the Notch signalling pathway determines cell fate during development. It is involved in cell identity, as well as differentiation, proliferation and eventual apoptosis of cells, also creating a boundary between cell populations allowing development. ${ }^{17}$

Mutations in Notch were first identified in 1915 and the following year it was first reported that these mutations caused malformations of Drosophila wings. ${ }^{7}$ DF Poulson, a professor at Yale University, was the first to identify links between Notch and neurogenic development. Poulson found that deletion of the Notch gene resulted in a hypertrophied central nervous system as a consequence of embryonic hypoderm differentiating into neuroblasts. Later the human $\mathrm{NOTCH}$ gene was cloned as part of research into human leukaemia and mutations in Notch were thought to be a causative factor. The cloning of this gene demonstrated how the Notch gene and all components of the Notch pathway in Drosophila are conserved to higher vertebrates. The discovery of Notch in Drosophila and consequent further research into the Notch pathway has highlighted its involvement in neurogenesis and neurone differentiation and, consequently, its overall importance in developmental neurobiology. In addition, it has been implicated in learning and memory, which can also be demonstrated in adult flies. After further research, it is now known that Notch plays a significant role in neuronal development and is also a major part of development of the heart, blood cells, skin and bone. ${ }^{7}$

\section{CIRCADIAN RHYTHMS}

Work by Seymour Benzer (1921-2007) in the 196070 s first formed the basis of our understanding of circadian rhythms. He designed the light countercurrent 
assay, still used in research today, as a simple behavioural test in Drosophila. In this assay he quantitatively measured the behavioural responses of flies to a light stimulus. He then compared these responses with those of mutant flies, including those with faulty phototaxis mechanisms and those with $\mathrm{X}$-chromosome mutations. He identified and then published a paper on the period (per) gene: the key to circadian rhythms. However it was many years later that homologous genes were found in mice and humans. ${ }^{7}$

\section{NEUROGENESIS AND EMBRYONIC DEVELOPMENT OF THE NERVOUS SYSTEM}

In the mid-1970s, further research into neurogenesis and embryonic development of the nervous system was carried out, again using Drosophila as the main model organism. Systematic chemical mutagenesis screens were carried out on the chromosomes of flies, with the aim of identifying genes involved in neurogenesis and embryonic development. Nüsslein-Volhard (a German biologist) and Wieschaus (an American developmental biologist), identified I 39 genes involved in signalling pathways that control larval development. These signalling pathways included Wingless, Hedgehog and Tumour growth factor and were found to be conserved to higher vertebrates, as part of differentiation of neuronal stem cells, neurogenesis and migration of neurones in the development of the nervous system. ${ }^{7}$

\section{THE CURRENT AND POTENTIAL USES FOR DROSOPHILA}

\section{Spinocerebellar ataxia 3}

Spinocerebellar ataxia type 3 (SCA3 or Machado-Joseph disease) is an autosomal, dominant inherited disease caused by repeats of the CAG trinucleotide at specific gene loci on chromosome 14, that result in the elongation of the polyglutamine portion of the ataxin-3 protein. ${ }^{18}$ This aetiological process is common to all the polyglutamine diseases, which also include Huntington's disease, spinal and bulbar muscular atrophy (SBMA), dentatorubral-pallidoluysian (DRPLA) and many types of spinocerebellar ataxia. ${ }^{19} \mathrm{All}$ these diseases are progressive and neurodegenerative. However the pattern of degeneration and therefore the clinical features differs between them. ${ }^{20}$ Spinocerebellar ataxia type 3 typically presents with dysarthria and both limb and gait ataxia, deteriorating over time. ${ }^{18}$ Drosophila melanogaster have been used to demonstrate these diseases; the first transgenic Drosophila model of SCA3 was created in 1998. ${ }^{2}$ Elongated polyglutamine proteins (disease proteins similar to that in human disease) 78 residues long were introduced into the flies using the SCA3 gene and these flies were compared with controls expressing proteins with polyglutamine runs of only 27 residues.
Features of SCA3 were reflected in these diseased flies, allowing for this model organism to be used in further research into the mechanisms of degeneration and neuronal loss in SCA3. ${ }^{20}$

\section{Huntington's disease}

Huntington's is another polyglutamine disease that has been studied using Drosophila melanogaster. It is a neurodegenerative disorder that has autosomal dominant inheritance and is clinically characterised by choreic movements that deteriorate over time, accompanied by cognitive decline and psychiatric disturbances. It is currently understood to be caused by abnormal polyglutamine expansion at the $\mathrm{N}$-terminus of the huntingtin protein. Expansion beyond 36 repeats results in the neurotoxic huntingtin protein found in Huntington's disease. ${ }^{21}$ Homologues of the huntingtin protein have been found in other vertebrates including mice, pufferfish and zebrafish, but because of the similarity in amino acid sequence, functional domains of the protein could not be easily distinguished. Studies using the more distantly related Drosophila has allowed for identification of conserved protein domains that are likely to be significant in the function of the huntingtin protein. ${ }^{22}$ Further work using Drosophila has led to conclusions that while the huntingtin protein is normally localised to the cytoplasm, mutated forms are localised to the nucleus. In addition, inclusions, which are large aggregates of the mutated protein and transcriptional co-activators, are found in neurones contributing to the pathology of this disease. ${ }^{23}$

Not only does the use of Drosophila melanogaster provide insight into the aetiology and pathogenesis of Huntington's disease, it also provides opportunities for research into therapeutic intervention. A study by Agrawal et al. ${ }^{24}$ proposed the effectiveness of combination drug regimens in the management of Huntington's disease; through their work with Drosophila, they identified two combination regimens as potential candidates. Agrawal et al. introduced mutant human huntingtin protein into Drosophila and analysed widespread neurodegeneration through survival assays, pseudopupil assays and climbing assays. They used drug-feeding experiments to assess the effects of combination drug regimens on disease progression and concluded that the two regimens tested (Congo red, cystamine and SAHA or SAHA combined with geldanamycin or Y-27632) suppressed neurodegeneration and therefore may be effective in reducing symptoms in people with Huntington's disease. ${ }^{24}$

\section{Alzheimer's disease}

Alzheimer's disease is becoming an ever-increasing problem, particularly with the ageing population of the Western world. Further research is therefore needed to aid us in understanding the disease and to develop 
interventions in the future. Drosophila melanogaster is an ideal model organism to demonstrate Alzheimer's disease as it can be crafted to show the signs of the progressive neuronal degeneration seen in this disease. The pathology involves formation of $\beta$-amyloid plaques composed of amyloid $\beta \mid-42$ and neurofibrillary tangles formed from hyperphosphorylated tau protein. Using genetic modification methods, such as the Gal4/UAS system, we can engineer Drosophila to manufacture amyloid $\beta_{1-42}$ and therefore amyloid plaques, giving a fly the equivalent of Alzheimer's disease in humans. The Gal4/UAS system can also be used to introduce R406W, the tauopathy-associated mutant of human tau, into Drosophila to replicate neurofibrillary tangles in a similar way. Assessment of these transgenic flies through longevity assays, locomotor and climbing assays and olfactory learning assays allows for further assessment of how Alzheimer's disease affects humans. Progressive locomotor decline can be observed in transgenic Drosophila through climbing assays. In addition, the crawling velocity of larvae can be measured to assess the effects of tau phosphorylation on motor neurones. Pavlovian olfactory learning assays, in which the Drosophila associated a certain odour with an electric shock and therefore learn to move towards the control odour in a T-maze, have shown impaired learning in flies containing $A \beta_{1-42}$. Histological assays demonstrate the changes that occur at the neuronal level at different stages of the disease progression. The use of Drosophila melanogaster in Alzheimer's disease research allows further understanding and potential discovery of new pathological processes and identification of new molecular targets for therapeutic development. ${ }^{25}$

\section{Parkinson's disease}

Another progressive neurodegenerative disease for which Drosophila melanogaster have been key in research and pathological development is PD. It is a chronic, progressive neurodegenerative disorder with worldwide distribution and increasing incidence with age. ${ }^{26}$ James Parkinson (1755-1844), an English apothecary and surgeon, first described this disease in his 1817 monograph Essay of the Shaking Palsy, ${ }^{27}$ in which he outlined the core clinical manifestations ${ }^{28}$ of this physically and socially debilitating disease. ${ }^{26}$ These include resting tremor, postural instability, muscular rigidity, bradykinesia and gait difficulties. The pathology of PD arises from progressive loss of dopaminergic neurones in the substantia nigra pars compacta $(\mathrm{SNc}){ }^{29}$

The majority of cases of PD are sporadic, with unknown aetiology. The environmental hypothesis suggests that these cases result from exposure to dopaminergic neurotoxins in the environment such as paraquat and rotenone, used as an herbicide and an insecticide respectively. Both are structurally similar to $\mathrm{MPP}+$, the active metabolite of MPTP, which can cause mitochondrial defects. ${ }^{28}$ However $5-10 \%$ of PD cases appear to have familial aetiology linked to the following genes: $\alpha$-synuclein, DJ-I, Parkin, PINKI and LRRK2. These have both recessive and dominant inheritance. Understanding of these genetic components has led to further awareness of the molecular pathogenesis of this disease. ${ }^{26}$ Drosophila melanogaster are being used today in the study of these familial causes of PD.

One of the genes linked to familial PD, $\alpha$-synuclein, is not found in Drosophila.This gene encodes a protein which is a component of Lewy bodies that are implicated in the pathology of PD. ${ }^{30}$ Feany and Bender ${ }^{31}$ introduced human $\alpha$-synuclein into Drosophila using the GAL4/UAS system to demonstrate neuronal degeneration, formation of inclusions and resultant defects in locomotion caused by $\alpha$-synuclein toxicity. They used tyrosine hydroxylase staining to analyse the dopaminergic neurones in sections of the fly brain, looking directly for neurodegeneration and used climbing assays to analyse the correlating locomotor response. ${ }^{31}$ Climbing assays were also used by Greene et al. ${ }^{31}$ in their study of parkin, mutations in which were already known to cause a form of early onset PD called autosomal recessive juvenile parkinsonism. They studied the longevity, flight and climbing abilities of Drosophila containing mutant parkin. Results demonstrated reduced longevity and defects in flight and climbing, as well as male sterility. As changes in the structure of mitochondria are a common feature of both muscle and germline pathology, they concluded that mitochondrial dysfunction must be significant in the mechanism of dopaminergic neuronal loss in PD. ${ }^{32}$

\section{CONCLUSION}

Drosophila melanogaster, or the common fruit fly, has been important in the study of genetics for over 100 years and neuroscience for less than that.' Work by Thomas Hunt Morgan and his students led to great advances in genetics including the construction of a genetic map and the recognition that ionising radiation is a causative factor in genetic mutations. ${ }^{15}$ Further insight into neurodevelopment and therefore functioning of the nervous system has been influenced significantly by work done in Drosophila melanogaster, leading to the research carried out today into neurodegenerative diseases such as Alzheimer's disease and PD. With the ageing population of theWestern World, further research into these diseases will be greatly influential and aided much by Drosophila melanogaster.

\section{Acknowledgement}

We are grateful for permission from Chris Elliot, University of York for use of Figure I and the Wellcome Library, London for use of Figure 2. 


\section{REFERENCES}

I Keller A. Drosophila melanogaster's history as a human commensal. Curr Biol 2007; 17:R77-R8I. http://dx.doi.org/I0.1016/j. cub.2006.12.03 I

2 Marsh JL, Thompson LM. Drosophila in the study of neurodegenerative disease. Neuron 2006; 52:169-78. http://dx.doi. org/l0.1016/j.neuron.2006.09.025

3 Chan HY, Bonini NM. Drosophila models of human neurodegenerative disease. Cell Death Differ 2000; 7:1075-80. http://dx.doi.org/I0.1038/sj.cdd.4400757

4 Whitworth AJ,Wes PD, Pallanck LJ. Drosophila models pioneer a new approach to drug discovery for Parkinson's disease. Drug Discov Today 2006; II:I19-26. http://dx.doi.org/I0.1016/SI3596446(05)03693-7

5 Sang TK, Jackson GR. Drosophila models of neurodegenerative disease. NeuroRx 2005; 2:438-46. http://dx.doi.org/I0.1602/ neurorx.2.3.438

6 Cauchi RJ, van den Heuvel M. The fly as a model for neurodegenerative diseases: is it worth the jump? Neurodegener Dis 2006; 3:338-56. http://dx.doi.org//0.I 159/000097303

7 Bellen HJ, Tong C, Tsuda H. I00 years of Drosophila research and its impact on vertebrate neuroscience: a history lesson for the future. Nat Rev Neurosci 20 1 0; I l:5 I4-22. http://dx.doi.org/ I0.1038/ nrn2839

8 Michán L, Sortibrán AC Rodríguez-Arnaiz R et al. Global Drosophila research: a bibliometric analysis. Drosophila Information Service 2010; 93:232-43.

9 Kohler RE. Drosophila: a life in the laboratory. J Hist Biol 1993; 26:28I-3 I0. http://dx.doi.org/I0.1007/BF0106/97/

10 Morgan TH. Sex limited inheritance in Drosophila. Science 1910; 32:I20-2. http://dx.doi.org/I0.1 I 26/science.32.812.120

II Green MM. 2010: a century of Drosophila genetics through the prism of the white gene. Genetics 2010; 184:3-7. http://dx.doi. org/I0.1534/genetics.109.110015

12 Lewis EB. Thomas Hunt Morgan and his legacy. Journal of Genetics 1998; 77:47-53. http://dx.doi.org/10.I007/BF02966589

13 Sturtevant $\mathrm{AH}$. The linear arrangement of xix sex-linked factors in Drosophila, as shown by their mode of association. Journal of Experimental Zoology 1913; 14:43-59. http://dx.doi.org/I0.1002/ jez.1400I40I04

14 Crow JF. Timeline: Hermann Joseph Muller, evolutionist. Nat Rev Genet 2005; 6:94I-5. http://dx.doi.org/10.1038/nrg I728

I5 Rubin GM, Lewis EB.A brief history of Drosophila's contributions to genome research. Science 2000; 287:2216-8. http://dx.doi. org/I0.II26/science.287.546I.22I6

16 Muller HJ.Artificial transmutation of the gene. Science 1927; 66:847. http://dx.doi.org/ I0.1 I26/science.66.1699.84

17 Gazave E, Lapébie P, Richards GS et al. Origin and evolution of the Notch signalling pathway: an overview from eukaryotic genomes. BMC Evol Biol 2009; 9:249. http://dx.doi.org/I0.I I86/I47I-2 |48-9-249
I8 Rüb U, de Vos RA, Schultz $C$ et al. Spinocerebellar ataxia type 3 (Machado-Joseph disease): severe destruction of the lateral reticular nucleus. Brain 2002; 125:21I5-24. http://dx.doi. org/I0.1093/brain/awf208

19 Pennuto M, Sambataro F. Pathogenesis of polyglutamine diseases. In: Encyclopedia of life sciences (ELS). Chichester: John Wiley \& Sons, Ltd; 20I0. pp. I-9. http://dx.doi.org//0.1002/97804700/5902. a002I486

20 Paulson HL, Bonini NM, Roth KA. Polyglutamine disease and neuronal cell death. Proc Natl Acad Sci USA 2000; 97:12957-8. http://dx.doi.org/I0.1073/pnas.210395797

2I Zhang S, Feany MB, Saraswati S et al. Inactivation of Drosophila huntingtin affects long-term adult functioning and the pathogenesis of Huntington's disease model. Dis Model Mech 2009; 2:247-66. http://dx.doi.org/I0.1242/dmm.000653

22 Li Z, Karlovich CA, Fish MP et al. A putative Drosophila homolog of the Huntington's disease gene. Hum Mol Genet I999; 8: I807-I5. http://dx.doi.org/10.1093/hmg/8.9.1807

23 Marsh JL, Pallos J,Thompson LM. Fly models of Huntington's disease. Hum Mol Genet 2003; I2:RI87-93. http://dx.doi.org/I0.1093/hmg/ ddg27l

24 Agrawal N, Pallos J, Slepko $\mathrm{N}$ et al. Identification of combinatorial drug regimens for treatment of Huntington's disease using Drosophila. Proc Natl Acad Sci USA 2005; 102:3777-8I. http://dx. doi.org/I0.1073/pnas.0500055102

25 Crowther DC, Page R, Chandraratna D et al. A Drosophila model of Alzheimer's disease. Methods Enzymol 2006; 4I 2:234-55. http:// dx.doi.org/I0.10I6/S0076-6879(06) I20I5-7

26 Thomas B, Beal MF. Parkinson's disease. Hum Mol Genet 2007; I6:RI84-94. http://dx.doi.org//0.1093/hmg/ddm I59

27 Parkinson J. An essay on the shaking palsy. J Neuropsychiatry Clin Neurosci 2002; 14:223-36. http://dx.doi.org/l0.II76/appi. neuropsych. 14.2.223

28 Dauer W, Przedborski S. Parkinson's disease: mechanisms and models. Neuron 2003; 39:889-909. http://dx.doi.org/l0.1016/ S0896-6273(03)00568-3

29 Wood-Kaczmar A, Gandhi S, Wood NW. Understanding the molecular causes of Parkinson's disease. Trends Mol Med 2006; 12:52 I-8. http://dx.doi.org/10.1016/j.molmed.2006.09.007

30 Park J, Kim Y, Chung J. Mitochondrial dysfunction and Parkinson's disease genes: insights from Drosophila. Dis Mod Mech 2009; 2:336-40. http://dx.doi.org//0.1242/dmm.003/78

3I Feany MB, Bender WW.A Drosophila model of Parkinson's disease. Nature 2000; 404:394-8. http://dx.doi.org//0.1038/35006074

32 Greene JC,Whitworth AJ, Kuo I et al. Mitochondrial pathology and apoptotic muscle degeneration in Drosophila parkin mutants. Proc Natl Acad Sci 2003; 100:4078-83. http://dx.doi.org//0.1073/ pnas. 0737556100 